
агропромышленного комплекса

Сбитнева O.A.,

ФГБОУ ВО «Пермский государственный аграрно-технологический университет

им. академика Д.Н. Прянишникова»,

Пермь, Российская Федерация.

(iD) ORCID: https://orcid.org/0000-0002-8463-1146, e-mail: oksana.sbitneva.73@mail.ru

Резюме: В статье рассматриваются проблемы развития фризических качеств, фризической подготовленности будущих специалистов агропромышленного комплекса. Раскрывается значимость фризических нагрузок на уровень физической подготовленности. Производится оценка уровня здоровья студентов, уровня фризической подготовленности. Рассматриваются особенности деятельности специалистов агропромышленного комплекса. Утверждается, что успешная профессиональная деятельность специалистов требует от выпускников теоретических знаний, функциональной устоиччвости, ффизической подготовленности, профрессионально важных психических качеств. Анализируются результаты контрольных нормативов по требованиям вуза. В статье также дается оценка развития основных двигательных качеств.

Методы исследования. В ходе исследования был проведен анализ полученных результатов. Применялся поиск, анализ, обобщение методической литературы; использован опрос и метод контрольных испытаний.

Результаты исследования. По результатам опроса по выявлению уровня здоровья, зафиксирован высокий показатель, имеющих какие-либо отклонения в состоянии здоровья постоянного или временного характера. При сдаче контрольных нормативов вуза был выявлен уровень развития фризических качеств, фризической подготовленности.

Делается вывод о том, что зафиксирован средний уровень развития быстроты, ловкости, силы. У выносливости и гибкости низкий уровень фризического развития. Физическая подготовленность является показателем общего состояния, уровня здоровья, физического развития, развития основных фризических качеств.

Ключевые слова: физическая подготовленность, фризические качества, специалисты агропромышленного комплекса, уровень здоровья, фризическая культура

Для цитирования: Сбитнева О.А. Оценка уровня фризической подготовленности будущих специалистов агропромышленного комплекса // Развитие образования. - 2021. - T. 4, №2. - C. 69-73. DOI 10.31483/r-98756. \title{
Assessment of the Level of Physical Fitness
of Future Specialists of the Agro-Industrial Complex Assessment of the Level of Physical Fitness
of Future Specialists of the Agro-Industrial Complex
}

Oksana A. Sbitneva

FSBEI of HE "Perm State Agrarian and Technological University named after academician D.N. Pryanishnikov"'",

Perm, Russian Federation.

ORCID: https://orcid.org/0000-0002-8463-1146, e-mail: oksana.sbitneva.73@mail.ru

\begin{abstract}
The article deals with the problems of the development of physical qualities, physical fitness of future specialists of the agro-industrial complex. The significance of physical activity on the level of physical fitness is revealed. The assessment of the level of health of students, the level of physical fitness is made. The features of the activity of specialists of the agro-industrial complex are considered. It is stated that successful professional activity of specialists requires from graduates theoretical knowledge, functional stability, physical fitness, professionally important mental qualities. The results of the control standards for the requirements of the university are analyzed. The article gives an assessment of the development of the main motor qualities.

Research methods. In the course of the study, the results were analyzed. We used search, analysis, generalization of methodological literature; we used a survey, a method of control tests.

The results of the study. According to the results of the survey to identify the level of health, a high indicator was recorded, having any deviations in the state of health of a permanent or temporary nature. When passing the control standards of the university, the level of development of physical qualities and physical fitness was revealed.

It is concluded that the average level of development of speed, agility, and strength is recorded. Endurance and flexibility have a low level of physical development. Physical fitness is an indicator of the general condition, level of health, physical development, development of basic physical qualities.

Keywords: physical fitness, physical qualities, specialists of the agro-industrial complex, level of health, physical culture.

For citation: Sbitneva O.A. (2021). Assessment of the Level of Physical Fitness of Future Specialists of the AgroIndustrial Complex. Razvitie obrazovaniya = Development of education, 4(2), 69-73. (In Russ.) DOI 10.31483/r-98756.
\end{abstract}

\section{Агропромышленность комплексӗн пулас специалисчӗсен хул-с̧урӑм аталанӑвӗн шайне хакласси}

Сбитнева О.А.,

АВ «Д.Н. Прянишников академик ячӗллӗ Пермь патшалӑх аграрипе технологи университечӗ» ФПБВУ,

Пермь, Рас̧с̧ей Федерацийӗ.

(iD ORCID: https://orcid.org/0000-0002-8463-1146, e-mail: oksana.sbitneva.73@mail.ru

Аннотаци: статьяра агропрмышленность комплексӗн пулас специалисчӗсене хул-с̧урӑм енчен аталантарассипе с̧ыхӑннӑ ыйтусене пӑхса тухнӑ. Хул-с̧урӑм енчен аталанма хул-с̧урӑма панӑ тием пӗлтерӗшлӗ пулнине ӑнлантарнӑ. Студентсен сывлӑх шайне тата хул-с̧урӑм енчен аталаннине хакланӑ. Агропромышленность комплексӗн 
специалисчӗсен ӗс̧ уйрӑмлахӗсене кӑтартнӑ. Автор с̧ирӗплетнӗ тӑрӑх, специалистсен профессипе с̧ыхӑннӑ ецс̆ӗн ӑнӑс̧лӑхӗ вӗсен теори пӗлӗвӗнчен, тӑтӑш ӗс̧леме пултарнинчен, хул-с̧урӑм с̧ирӗплӗхӗпе пис̧ӗлӗхӗнчен, профессие тивӗс̧терекен психика пахалӑхӗ пурринчен килет. Аслӑ шкула тиве̌с̧терекен нормативсене тӗрӗсленин результачӗсене тишкернӗ. Кунсӑр пусне статьяра хусканӑвӑн тӗп е̌нӗсем епле аталаннине хакланӑ.

Тӗпчев меслечӗ. Тӗпчев вӑхӑтӗнче автор результатсене тишкернӗ. Усӑ курнӑ меслетсем: шырав, тишкерӱ, методика литературине тишкерсе пӗтӗмлетни. Ыйту меслечӗпе тата тӗрӗслевпе усӑ курнӑ.

Тӗпчев результачӗ. Сывлӑх мӗнле иккенне палӑртас тӗллевпе панӑ ыйту хуравӗсенче пысӑк кӑтарту асӑрханӑ Сывлӑх енчен ялан е вӑхӑт-вӑхӑт палӑракан кӑлтӑк пур с̧ынсене тупса палӑртман. Норматив показателӗсене тӗрӗсленӗ чухне студентсен вӑй пахалӑхне, хул-с̧урӑм аталанӑвне тупса палӑртнӑ. Пӗтӗмлетӳре каланӑ тӑрӑх, тӗрӗсленӗ с̧ынсен хӑвӑртлӑхӗ, вичкӗнлӗхӗ, вӑйӗ вӑтам шайра тӑрать. Чӑтӑмлӑхпа пис̧ӗлӗхӗн аталанӑвӗ аял шайра пулнипе палӑрать. Хул-с̧урӑм енчен аталанни тӑрӑх с̧ын сывлӗхӗн шайне, вӑй аталанӑвне, вӑй-халӑн тӗп енӗсем епле иккенне пӗлме пулать.

Tӗп сӑмахсем: хул-с̧урӑм вӑйне аталантарса с̧итерни, хул-с̧урӑм аталанӑвӗн пахалӑмхӗ, агропромышленность комплексӗн специалисчӗсем, сывлӑх шайӗ, физкультура.

Цитатӑлама: Сбитнева О.А. Агропромышленность комплексӗн пулас специалисчӗсен хул-суурӑм аталанӑвӗн шайне хакласси // Вӗренӳ аталанӑвӗ. - 2021. - T. 4, №2. - C. 69-73. DOI 10.31483/r-98756.

\section{Введение}

Прогрессивный ритм жизни студентов требует от студентов физической активности, физической подготовленности. Физическая активность - это индивидуальная деятельность, направленная на достижение физических качеств, необходимых для достаточного поддержания высокого уровня здоровья, физического развития и физической подготовленности. Уровень развития физических качеств, физической подготовленности обеспечивает гармоничное физическое развитие, повышает уровень состояния здоровья, оказывая положительное воздействие на все функциональные системы организма, умственную и физическую работоспособность. Результатом деятельности физической подготовленности является степень совершенства двигательных умений и навыков, высокий уровень развития жизненных сил, спортивных достижений; нравственного, эстетического, интеллектуального развития. Известно, что адаптация человека к условиям производства без специальной психофизической подготовки может длиться от 1 года до 7 лет. Поэтому высшие учебные заведения развивают специфические физические качества, физиологические функции, психические качества у студентов, передают знания умения и навыки, необходимые для эффективного овладения конкретной профессией [1]. Деятельность специалистов агропромышленного комплекса является смешанным трудом. Это связано с замерами, различными обследованиями, расчетами, что требует умственного напряжения и физической выносливости. Производственная деятельность агрономов ведется во время посевных и уборочных работ, в условиях различного температурного диапазона (от - 30 до + $36^{\circ} \mathrm{C}$ ), высокой влажности, резких колебаний атмосферного давления, сильных ветров и т. д. Их рабочий день не является нормированным. Среднее расстояние, пройденное за смену, рассчитывается от 6 до 15 км (около 24000 шагов в день) [2]. Высокие и низкие температуры, вызывающие перегрев и переохлаждение, колебания атмосферного давления, влажность - все это неизбежно вызывает усталость и снижение работоспособности. В этих условиях труда наблюдается спад умственной и физической подготовленности, могут возникать респираторные, нервные и пищеварительные заболевания. Эта профессиональная работа вызвана неритмичностью, вызывая значительное напряжение костно-мышечной системы, которая в дальнейшем может обуславливать возникновение аритмий, нарушенную суточную двигательную активность, что приводит к негативным изменениям в физическом состоянии специалистов.

Для оценки уровня физической подготовленности будущих специалистов агромышленного комплекса был поставлен ряд задач:

1. Изучить и проанализировать методическую литературу по теме.

2. Выявить уровень здоровья обучающихся.

3. Выявить уровень физической подготовленности студентов

4. Изучить особенности деятельности специалистов агропромышленного комплекса.

5. Проанализировать полученные результаты.

\section{Методы исследования}

В исследовании был использован метод контрольных испытаний, метод опроса, сравнительного анализа, педагогического наблюдения.

\section{Результаты исследования}

По результатам опроса респондентов Пермского

Таблица 1

Уровень здоровья

Table 1

Health level

\begin{tabular}{|c|c|c|c|}
\hline \multicolumn{3}{|c|}{ Группы здоровья } \\
\hline Основная группа & Подготовительная группа & Специальная группа & Освобождены \\
\hline $35,5 \%$ & $32,3 \%$ & $20,5 \%$ & $11,7 \%$ \\
\hline
\end{tabular}


ГАТУ им. Д.Н. Прянишникова был выявлен уровень здоровья (табл. 1). Возраст 34 испытуемых составляет 18-23 года.

По результатам проведённого опроса можно сделать вывод о том, что большинство обучающихся - 52,8\% имеют какие-либо оклонения в состоянии здоровья постоянного или временного характера, ограничения по занятиям физической культурой, 11,7\% полностью освобождены от занятий по состоянию здоровья, 35,5\% не имеют отклонений в физическом развитии, состоянии здоровья, нет ограничений по занятиям физической культурой. Сохранение и укрепление здоровья - одна из самых важных задач современного студенчества. Приоритетными в подготовке специалистов агропромышленного комплекса являются общая ловкость, ловкость рук и пальцев, быстрота, точность движений и двигательных реакций, развитие общей выносливости. Среди психофизических функций важнейшей является внимание (широта распределения, переключение, концентрация). В психических функциях приоритет отдается оперативному мышлению, памяти и коммуникации [4]. Для исследования были выбраны тесты, которые широко представлены в теории и практике физического воспитания. Используя контрольные тесты был выявлен уровень физической подготовенности обучающихся в Пермском ГАТУ им. Д.Н. Прянишникова. В исследовании приняли участие 34 человека в возрасте 18-23 лет. Уровень физической подготовенности состоит из уровня развития быстроты (табл. 2), уровня развития выносливости (табл. 3), уровня развития гибкости ( табл. 4), уровня развития ловкости (табл. 5) и уровня развития силы (табл. 6).

\section{Выводы}

По результатам проведённого исследования можно сделать вывод о том, что быстрота, ловкость и сила у обучающихся развиты на среднем уровне физического развития, выносливость и гибкость на низком уровне.

Таблица 2

Уровень развития быстротьл (количество уч-ся \%)

Table 2

Level of speed development ( number of students \%)

\begin{tabular}{|c|c|c|c|c|c|c|c|c|c|c|c|c|}
\hline Тест & \multicolumn{2}{|c|}{5} & \multicolumn{2}{|c|}{4} & \multicolumn{2}{|c|}{3} & \multicolumn{2}{|c|}{2} & \multicolumn{2}{|c|}{1} & $\begin{array}{c}\text { Не } \\
\text { выполнили } \\
\text { норматив }\end{array}$ & \\
\hline \multirow{2}{*}{$\begin{array}{c}\text { Бег } \\
100 \mathrm{M}\end{array}$} & M & Д & M & Д & $\mathrm{M}$ & Д & M & Д & M & Д & M & Д \\
\hline & 11,7 & 11,7 & 29,4 & 29,4 & 23,5 & 26,4 & 14,7 & 14,7 & 17,6 & 14,7 & 3,1 & 3,1 \\
\hline
\end{tabular}

Уровень развития выносливости (кол-во уч-ся \%)

Таблица3

Table 3

Level of endurance development ( number of students \%)

\begin{tabular}{|c|c|c|c|c|c|c|c|c|c|c|c|c|} 
Тест & \multicolumn{3}{|c|}{5} & \multicolumn{3}{|c|}{4} & \multicolumn{2}{|c|}{3} & \multicolumn{3}{|c|}{1} & \multicolumn{3}{|c|}{ Не выполнили } \\
норматив
\end{tabular}

Уровень развития гибкости (кол-во уч-ся \%)

Таблица4

Table 4

Level of flexibility development ( number of students \%)

\begin{tabular}{|c|c|c|c|c|c|c|c|c|c|c|c|c|}
\hline Тест & \multicolumn{2}{|c|}{5} & \multicolumn{2}{|c|}{4} & \multicolumn{2}{|c|}{3} & \multicolumn{2}{|c|}{2} & \multicolumn{2}{|c|}{1} & \multicolumn{2}{|c|}{$\begin{array}{c}\text { Не } \\
\text { выполнили } \\
\text { норматив }\end{array}$} \\
\hline \multirow{2}{*}{$\begin{array}{l}\text { Наклон вперед из положения стоя } \\
\text { на гимнастической скамье }\end{array}$} & M & Д & $\mathrm{M}$ & Д & M & Д & M & Д & M & Д & M & Д \\
\hline & 14,7 & 17,6 & 5,8 & 14,7 & 29,4 & 29,4 & 23,5 & 23,5 & 20,5 & 11,7 & 6,1 & 3,1 \\
\hline
\end{tabular}

Уровень развития ловкости (кол-во уч-ся \%)

Таблица 5

Level of dexterity development ( number of students \%)

Table 5

\begin{tabular}{|c|c|c|c|c|c|c|c|c|c|c|c|c|c|}
\multirow{2}{*}{ Тест } & \multicolumn{2}{|c|}{5} & \multicolumn{2}{|c|}{4} & \multicolumn{3}{|c|}{ Не } \\
выполнили \\
норматив
\end{tabular}


Level of strength development ( number of students \%)

\begin{tabular}{|c|c|c|c|c|c|c|c|c|c|c|c|c|}
\hline Тест & \multicolumn{2}{|c|}{5} & \multicolumn{2}{|c|}{4} & \multicolumn{2}{|c|}{3} & \multicolumn{2}{|c|}{0} & \multicolumn{2}{|c|}{1} & \multicolumn{2}{|c|}{$\begin{array}{c}\text { Не } \\
\text { выполнили } \\
\text { норматив }\end{array}$} \\
\hline \multirow{2}{*}{$\begin{array}{l}\text { Подтягивание (ю) Сед из положения } \\
\text { лежа на спине (д) }\end{array}$} & M & Д & M & Д & $\mathrm{M}$ & Д & $\mathrm{M}$ & Д & $\mathrm{M}$ & Д & $\mathrm{M}$ & Д \\
\hline & 382 & 382 & 23,5 & 23,5 & 20,5 & 23,5 & 8,8 & 11,7 & 5,8 & 3,1 & 3,2 & - \\
\hline
\end{tabular}

Комплекс упражнений на развитие выносливости

Таблица 7

A set of exercises for the development of endurance

Table 7

\begin{tabular}{|c|c|}
\hline Длительный бег & $1-1.5$ часа \\
\hline Бег 1000 м & $1-2$ серии, отдых до полного восстановления \\
\hline Смешанное передвижение (кросс-ходьба) & Непрерывное передвижение 1ччас \\
\hline Велосипед & $3-5$ км \\
\hline Бег по пересеченной местности & $3-5$ км \\
\hline фартлек & $3-5$ км \\
\hline Скандинавская ходьба & $3-5$ мин, 5-7 серий \\
\hline Подьем по лестние & $100,120,150$ прыжков.Отдых 10 сек. \\
\hline Прыжки на скакалке & $15-20$ повторений, 3-4 серии \\
\hline $3-4$ серии & $30-40$ прыжков, 3-4 серии \\
\hline Упор присев, упор лежа & $15-30$ сек, 3-4 серии \\
\hline Прыжки через скамейку & \\
\hline Прыжки с продвижением вперед & \\
\hline
\end{tabular}

Комплекс упражнений на развитие гибкости

Таблица 8

Table 8

A set of exercises for the development of flexibility

\begin{tabular}{|c|c|}
\hline Наклоны головы в стороны с фиксацией & $15-20$ сек, 3-4 серии \\
\hline Вращения запястий, локтевы, плечевых суставов & $10-12$ раз \\
\hline Наклоны в сторону, руки вверх & Удержание 15-20 сек, 4 серии \\
\hline Наклон вперед, руки вперед & Удержание 15-20 сек, 3-4 серии \\
\hline Сидя на полу, наклон вперед, руки вперед, ладони на полу & Удержание 15-20 сек, 3-4 серии \\
\hline Стоя, наклон вперед, руки в упор перед собой & Удержание 15-20 сек, 3-4 серии \\
\hline Сидя на полу, ноги врозь. Наклоны к правой, левой вперед & $10-12$ раз \\
\hline Сидя на полу, наклон вперед с фиксацией стоп & Удержание 15-20 сек, 3-4 серии \\
\hline Лежа на животе, сгибание в коленном суставе, & $10-12$ раз \\
\hline тяга ноги к ягодице & Удержание 15-20 сек, 3-4 серии \\
\hline Выпады вперед & Удержание 15-20 сек, 3-4 серии \\
\hline Выпады в стороны & $30-40$ прыжков, 3-4 серии \\
\hline Прыжки через скамейку & \\
\hline
\end{tabular}


После данной диагностики студентам были предложены комплексы упражнений на развитие выносливости (табл. 7) и гибкости (табл. 8).

Физическое воспитание, обеспечивая сохранение и укрепление здоровья, оказывает влияние на рост учебно-трудовой активности и работоспособности студентов. Усвоение для будущей профессиональной деятельности необходимых знаний, умений и навыков в области физической культуры расширяет научно-образовательный потенциал будущих специалистов, способствует эффективной творческой и производственной деятельности, обеспечивает длительное сохранение трудоспособности. В современных условиях важное значение приобретает проблема формирования профессиональных качеств и навыков, повышения устойчивости организма человека к различным профессиональным заболеваниям на основе широкого использования средств и методов физической культуры. Спортивные нагрузки после основ-ных занятий - это один из способов коррекции психического состояния, снятия напряжения накопившегося в течение учебного дня [3]. Двигательная ак-тивность - это один из значимых компонентов здорового режима жизни студентов, в основе которого разумное, соответствующее полу, возрасту, состо-янию здоровья систематическое использование средств физической культуры и спорта.

\section{Список литературы}

1. Войтехов Д.Д. Социально-гигиеническое исследование условий труда, быта и состояния здоровья - работников умственного труда / Д.Д.Войтехов // Годовой отчёт НИИ гигиены им. Ф.Ф.Эрисмана. - М., $2016 .-64$ с.

2. Ванюшин Ю.С. Физическая культура: учебное пособие для студентов аграрных вузов / Ю.С. Ванюшин, М.Ю. Ванюшин, Р.Р. Хайруллин. - Казань: Изд-во Казанского ГАУ, 2011. - 98 с.

3. Виленский М.Я. Физическая культура и здоровый образ жизни студента / М.Я. Виленский, А.Г. Горшков. M.: 2007. -218.

4. Евсеев С.П. Физическая культура в системе высшего профессионального образования: реалии и перспективы: монография / С.П. Евсеев. - СПб.: ГАФК им. П.Ф.Лесгафта, 2015. - 144 с.

\section{References:}

1. Voitekhov D.D. (2016). Sotsial'n-o-gigien-icheskoe issledovan-ie uslovii tr-uda, byta i sostoianiia zdorov'ia. Godovoi otchiot NII gigieny im. F.F.Erismana, 64. M.

2. Vaniushin Iu.S., Vaniushin M. u., \& Khairullin R.R. (2011). Fizicheskaia kul'tura: uchebnoe posobie dlia studentov agrarnykh vuzov., 98. Kazan': Izd-vo Kazanskogo GAU.

3. Vilenskii M.Ia., \& Gorshkov A.G. Fizicheskaia kul'tura i zdorovyi obraz zhizni studenta.

4. Evseev S.P. (2015). Fizicheskaia kul'tura v sisteme vysshego professional'nogo obrazovaniia: realii i perspektivy: monografiia., 144. SPb.: GAFK im. P.F.Lesgafta.

\begin{tabular}{|c|c|c|}
\hline $\begin{array}{l}\text { Информация об авторе } \\
\text { Сбитнева Оксана Анатольевна - } \\
\text { старший преподаватель, ФГБОУ } \\
\text { ВО «Пермский государственный } \\
\text { аграрно-технологический универ- } \\
\text { ситет им. академика Д.Н. Пряниш- } \\
\text { никова», }\end{array}$ & $\begin{array}{l}\text { Information about the author } \\
\text { Oksana A. Sbitneva - senior } \\
\text { lecturer of FSBEI of HE "Perm } \\
\text { State Agrarian and Technological } \\
\text { University named after academician } \\
\text { D.N. Pryanishnikov", } \\
\text { Perm, Russian Federation. }\end{array}$ & $\begin{array}{l}\text { с̧инчен пе̌лтерни } \\
\text { Оксана Анатольевна - } \\
\text { даватель, АВ } \\
\text { нишников ячӗллӗ Пермь } \\
\text { Іграрипе технологи } \\
\text { ечӗ») ФПАВУ, } \\
\text { с̧ей Федерацийӗ. }\end{array}$ \\
\hline
\end{tabular}

Поступила в редакцию / Received / Редакцие с̧итнӗ 28.05.2021

Принята к публикации / Accepted / Пичетлеме йышӑннӑ 22.06.2021

Опубликована / Published / Пичетленсе тухнӑ 23.06.2021 